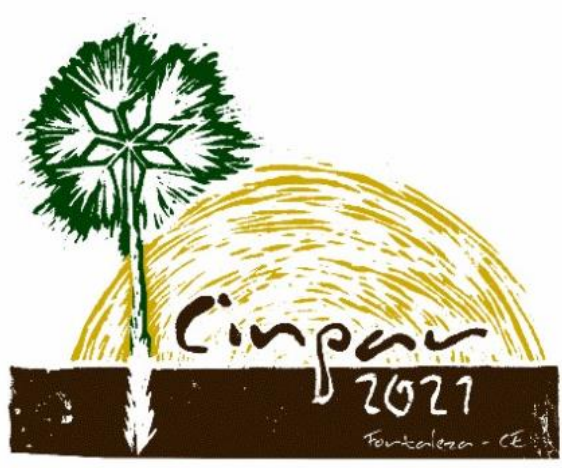

XVII Congresso Internacional sobre Patologia e

Reabilitação das Construções

XVII Congreso Internacional sobre Patología y Rehabilitación de las Construcciones

XVII International Conference on Pathology and Constructions Rehabilitation

FORTALEZA (Brasil), 3 a 5 de junho de 2021

https://doi.org/10.4322/CINPAR.2021.019

\title{
Reaproveitamento de Cascas de Marisco na Produção de Concreto
}

\section{Reuse Of Seafood Shells In Concrete Production}

\author{
Bianca DA COSTA FERREIRA ${ }^{1}$, Rayssy JARDANNY MIRANDA DA SILVA ${ }^{2}$ \\ ${ }^{1}$ Bssp centro educacional, Teresina, Brasil, biancaferreirajjs@gmail.com \\ ${ }^{2}$ Bssp centro educacional, Teresina, Brasil, rayssy_jdn@hotmail.com
}

\begin{abstract}
Resumo: As conchas de mariscos são formadas basicamente por carbonato de cálcio (CaCO3), que é empregado como matéria prima para diversos produtos, estas são facilmente encontradas na cidade de Luís Correia -PI. As cascas são descartadas no meio ambiente gerando impactos ambientais, além do surgimento de enfermidades, provenientes de animais e insetos. $O$ objetivo desta pesquisa é criar uma alternativa para o reaproveitamento desses resíduos no âmbito da construção civil como material para a produção de concreto, além de reduzir o impacto ambiental causado. Foi realizado a confecção de 12 corpos de provas com 4 traços aos 14 dias, onde estes passaram por ensaios de compressão simples e granulometria para os agregados. Verificou-se que a adição de $10 \%$ de pó de conchas de mariscos em substituição a areia teve uma resistência superior. As adições de 5\% e 15\% apresentaram uma redução ao concreto convencional.
\end{abstract}

Palavras Chaves: sustentável, resíduos, conchas de mariscos, construção civil.

Abstract: Shellfish are basically composed of calcium carbonate ( $\mathrm{CaCO} 3)$ which is used as raw material for various products, these are easily found in the city of Luís Correia -PI. The barks are discarded in the environment generating environmental impacts, besides the appearance of diseases, coming from animals and insects. The objective of this research is to create an alternative for the reuse of these residues in the scope of civil construction as material to produce concrete, in addition to reducing the environmental impact caused. It was carried out the construction of 12 test bodies with 4 traces at 14 days, where they passed through tests of simple compression and granulometry for the aggregates. It was found that the addition of $10 \%$ of shellfish powder in substitution of the sand had superior strength. The additions of $5 \%$ and $15 \%$ showed a reduction to conventional concrete.

Keywords: sustainable, waste, seafood shells, civil construction.

\section{Introdução}

$\mathrm{Na}$ busca de atender suas necessidades o ser humano durante muito tempo não se preocupou com o modo de uso dos recursos naturais, e por conta de sua habilidade de adequação e mudança do meio circundante, fez com que ocorressem alterações significativas na natureza, assim, consequentemente, gerando e acentuando o impacto ambiental (MOTA et al., 2009).

O processo de industrialização acompanhado com o crescimento demográfico, ocasionou uma amplificação no quesito geração de resíduos sólidos. Esse contexto fulminou o desenvolvimento da consciência ambiental, surgindo a partir daí legislações ambientais mais severas, obrigando o gerador de resíduos a tratar eles para dispô-los de maneira adequada sem degradar o meio ambiente, gerando assim novos custos (TESSARI, 2006).

Consequentemente, as empresas sentem a necessidade de implantar medidas sustentáveis a fim de reduzir o impacto ambiental, minimizando a produção de resíduos, assim como processos de disposição final, reciclagem e reaproveitamento. Dessa forma, atendendo as exigências dos órgãos ambientais e, podendo 
até obter lucros com a comercialização dos resíduos ou redução de gastos relativos a matéria-prima (ÂNGULO, 2001).

A construção civil é um importante segmento industrial brasileiro, contudo é uma atividade geradora de impactos ambientais. Uma obra envolve variadas etapas com interação com o meio ambiente, essas etapas podem variar desde a limpeza do terreno, regularização do relevo, execução de serviços, consumo de recursos naturais para execução dos elementos de concreto, etc, que, por decorrência, ocasiona a geração de resíduos sólidos (VECHI; GALLARDO; TEIXEIRA, 2016). Considerando seu elevado consumo e diversidade de materiais absorvidos, é um mercado potencial para absorver os subprodutos dos processos de tratamento de resíduos sólidos (ROCHA; CHERIAF, 2003).

Como qualquer outra atividade a maricultura gera resíduos, que são principalmente cascas de moluscos (SANTOS, 2013). A mariscagem é uma atividade para subsistência e comercialização realizada pelas famílias ribeirinhas. A Companhia de Desenvolvimento do Vale do São Francisco e do Parnaíba (CODEVASF) como forma de apoio as famílias produtoras, forneceu àquela comunidade forrageiras para a transformação das conchas de marisco em pó para assim evitar seu descarte inadequado (CODEVASF, 2013). As conchas de marisco são compostas principalmente pelo carbonato de cálcio ( $\mathrm{CaCo} 3)$, este mineral tem ampla diversidade de uso e variadas aplicações, desde materiais de contrição

à produção de alimentos; agricultura; tratamento de água; indústria farmacêutica (SANTOS et al., 2017).

No início dos anos 80 a Coréia já iniciava os primeiros estudos visando a solução para utilização de conchas, devido à grande produção do país. Pesquisas mostraram que as conchas quando submetidas a temperaturas de $750^{\circ} \mathrm{C}$ durante um período de uma hora numa atmosfera de nitrogênio, transformaram-se em um produto de grande importância para o controle da eutrofização de águas. Ainda foi verificada a possibilidade de substituir agregados na produção de cimento por conchas moídas, uma alternativa ideal em situações onde há pouca disponibilidade de areia (SANT'ANNA, 2007).

No Brasil, no estado do Rio Grande, pesquisadores da Universidade do Sul de Santa Catarina (UNISUL) mostraram a viabilidade do uso de cascas de ostras e mexilhões na fabricação de blocos de concreto e de blocos para a pavimentação. As cascas forram submetidas a um processo de lavagem, depois expostas ao sol para secar e posteriormente trituradas em moinho. Após esse processo o material resultante foi adicionado aos demais componentes da fabricação de blocos e pavimentos de concreto. Esses blocos foram submetidos a testes de absorção de água e resistência à compressão. Os resultados adquiridos pelo estudo apontaram que estes produtos são altamente viáveis, se encaixando nas normas da ABNT. Dessa forma, sendo mais uma alternativa para o uso dos resíduos provenientes da maricultura (BATISTA et. al, 2009).

Tendo em vista a gama de variedades de uso do carbonato de cálcio, principal componente das conchas de mariscos, juntamente com a consciência de desenvolvimento sustentável e a necessidade de novos métodos alternativos para formulação do concreto, o objetivo desse trabalho é reutilizar as conchas de marisco como material na confecção de concreto e avaliar se o produto atende as normas para uso em obras de construção.

\section{Materiais e métodos}

\subsection{Materiais}

\subsection{1 - Cimento}

O cimento utilizado no ensaio foi do tipo CP V-ARI, proporcionando altas resistências já nos primeiros dias de aplicação. A alta resistência inicial ocorre devido a dosagem diferente de calcário e argila na produção do clínquer, assim como pela moagem mais fina do cimento, que ao reagir com a água, o cimento vai adquirir elevadas resistências de forma mais rápida (PORTAL CONCRETO, 2016).

\subsection{2 - Água}

A água referente ao experimento foi disponibilizada no laboratório de Materiais de Construção Civil do Centro Universitário Santo Agostinho, em Teresina (PI).

\subsection{3 - Areia}


A areia empregada foi fornecida no laboratório de Materiais de Construção Civil do Centro Universitário Santo Agostinho, em Teresina (PI).

2.1.4 - Pó de conchas de mariscos

Os resíduos reciclados são referentes ao trituramento das conchas de mariscos que se resultam em pó, onde este não tem uma destinação correta, gerando um impacto ambiental. A alternativa é utilizar este resíduo em substituição a areia na produção do concreto. As conchas de mariscos são coletadas pelas comunidades ribeirinhas, estas situadas em Luís Correia, litoral do Piauí. O pó das conchas empregado é fornecido através de forrageiras pela Companhia de Desenvolvimento do Vale do São Francisco e do Parnaíba (CODEVASF).

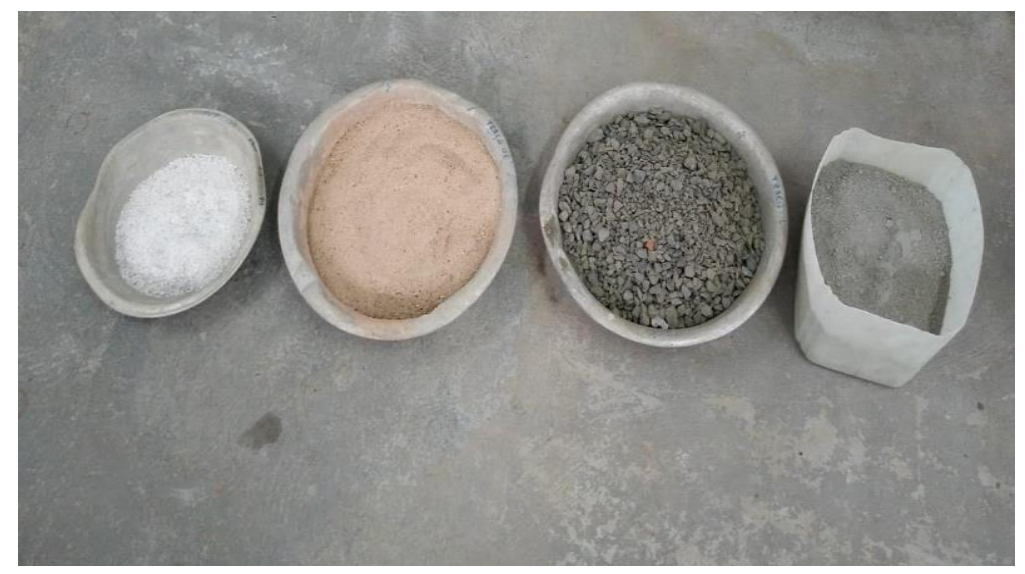

Figura 1 - Materiais utilizados na pesquisa (Próprio autor, 2019)

\subsection{Métodos}

\subsection{1 - Traços estudados}

O traço utilizado foi 1:1,4:1,9 (cimento: areia: brita) para todos os ensaios, utilizando com $5 \mathrm{~kg}$ de cimento, $7 \mathrm{~kg}$ de areia, 9,5kg de brita e $2220 \mathrm{ml}$ de água, isto é, com fator a/c de 0,50. O pó das conchas foi analisado no experimento utilizando as porcentagens de $5 \%, 10 \%$ e $15 \%$ em substituição da areia.

\subsection{2 - Granulometria da areia}

O ensaio realizado para determinar a composição granulométrica da areia foi realizado seguindo as prescrições contidas na NBR 7217:1987. Primeiramente foi realizado o processo de quarteamento do material, uma técnica empregada para reduzir a massa da amostra em frações menores, obtendo-se uma amostra final de $7 \mathrm{~kg}$ de areia. A amostra passou pelo processo de secagem em estufa, durante um período de 24 horas em temperaturas de 100 a 120 ㅇ. Em seguida a amostra passou pelo processo de peneiramento usando o jogo de peneiras com aberturas $(\mathrm{mm})$ de 2,$4 ; 2 ; 1,2 ; 0,600 ; 0,420 ; 0,300 ; 0,177 ; 0,150 ; 0,075$ e fundo.

\subsection{3 - Granulometria da brita}

O ensaio realizado para determinar a composição granulométrica da brita foi realizado seguindo as prescrições contidas na NBR 7217:1987. O material foi separado em uma amostra de $5 \mathrm{~kg}$, que foi peneirada usando peneiras de aberturas (mm): $50 ; 381 ; 31,5 ; 25,4 ; 19 ; 12,7 ; 9,5 ; 6,3 ; 4,76 ; 2,36 ; 2$ e fundo.

\subsection{4 - Granulometria do pó das conchas de mariscos}

O ensaio para a determinação da composição granulométrica do pó da concha de marisco foi realizado seguindo as prescrições presentes na NBR 7217:1987. Utilizou-se uma amostra do material de $5 \mathrm{~kg}$, onde foi peneirada com aberturas (mm) de 2,4; $2 ; 1,2 ; 0,600 ; 0,420 ; 0,300 ; 0,177 ; 0,150 ; 0,075$ e fundo.

\subsection{5 - Resistência à compressão}


O ensaio de resistência a compressão foi realizando utilizando 3 corpos de prova de concreto convencional com $5 \mathrm{~kg}$ de cimento, $7 \mathrm{~kg}$ de areia, $9,5 \mathrm{~kg}$ de brita e $2220 \mathrm{ml}$ de água, 3 corpos de prova de concreto com $5 \mathrm{~kg}$ de cimento, $6,650 \mathrm{~kg}$ de areia, $350 \mathrm{~g}$ de pó das conchas de mariscos, e $2220 \mathrm{ml}$ de água, 3 corpos de prova de concreto com $5 \mathrm{~kg}$ de cimento, $6,300 \mathrm{~kg}$ de areia, $700 \mathrm{~g}$ de pó das conchas de mariscos, e $2220 \mathrm{ml}$ de água e 3 corpos de prova de concreto com $5 \mathrm{~kg}$ de cimento, 5,950kg de areia, 1,050kg de pó das conchas de mariscos e $2220 \mathrm{ml}$ de água, totalizando 12 corpos de prova que foram moldados (Figura 3 ). Para o ensaio de caracterização no estado endurecido foram utilizados corpos de prova cilíndricos de $10 \times 20 \mathrm{~cm}(10 \mathrm{~cm}$ de diâmetro e $20 \mathrm{~cm}$ de altura) de dimensões, e seguiram-se as prescrições da norma NBR 7215:1996. O ensaio foi feito em relação aos 14 dias de cura dos corpos de prova.

\section{Resultados e Discussão}

\subsection{Análise granulométrica da areia}

A granulometria da areia utilizada é aceita pelos limites prescritos para agregados miúdos das normas ABNT, onde foi realizado segundo as prescrições da NBR 7217:1987.

\subsection{Análise granulométrica da brita}

O ensaio realizado para determinar a composição granulométrica da brita foi realizado seguindo as prescrições contidas na NBR 7217:1987.

\subsection{Análise granulométrica do pó das conchas de mariscos}

O ensaio para a determinação da composição granulométrica do pó da concha de marisco foi realizado seguindo as prescrições presentes na NBR 7217:1987. A Tabela 1 abaixo trata-se dos resultados adquiridos com o ensaio de peneiramento.

\section{AMOSTRA 01 - PÓ DAS CONCHAS DE MARISCOS}

Tabela 1 - Composição granulométrica do pó de marisco

\begin{tabular}{|c|c|c|c|c|}
\hline PENEIRA ( $\left.{ }^{\circ}\right)$ & Abertura $(\mathrm{mm})$ & $\begin{array}{c}\text { PESO RETIDO } \\
(\mathrm{kg})\end{array}$ & $\%$ retida & \% acumulada \\
\hline 8 & 2,400 & 0,294 & 5,89 & 5,89 \\
\hline 10 & 2,000 & 0,151 & 3,02 & 8,91 \\
\hline 16 & 1,200 & 0,935 & 18,72 & 27,63 \\
\hline 30 & 0,600 & 2,137 & 42,78 & 70,41 \\
\hline 40 & 0,420 & 0,385 & 7,71 & 78,12 \\
\hline 50 & 0,300 & 0,311 & 6,23 & 84,34 \\
\hline 80 & 0,177 & 0,559 & 11,19 & 95,54 \\
\hline 100 & 0,150 & 0,094 & 1,88 & 97,42 \\
\hline 200 mesh & 0,075 & 0,087 & 1,74 & 99,16 \\
\hline Fundo & Fundo & 0,042 & 0,84 & 100,00 \\
\hline TOTAL & & 5,00 & 100,00 & \\
\hline
\end{tabular}




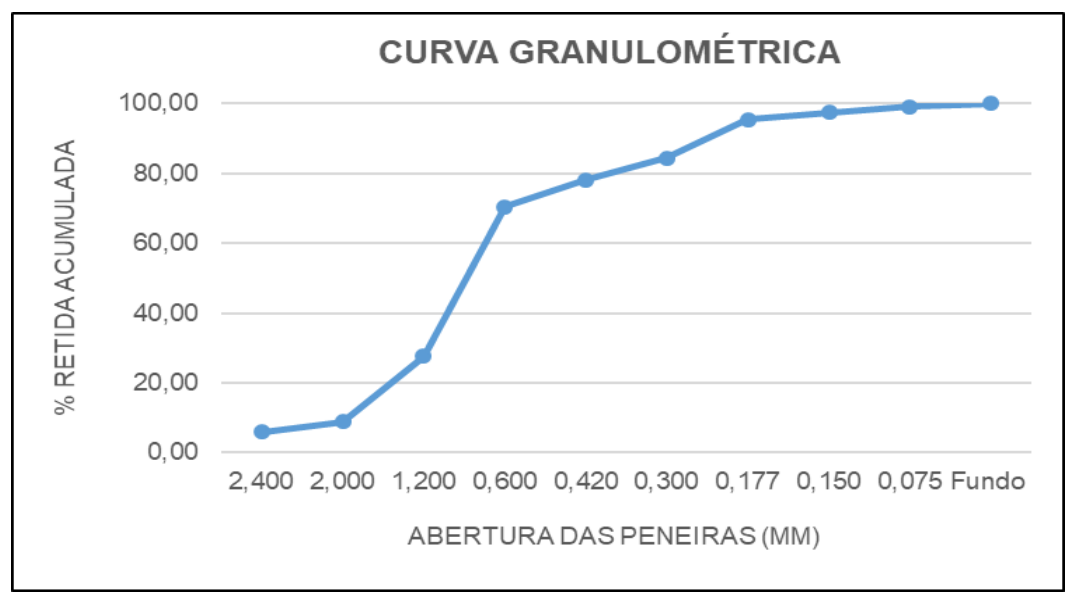

Figura 2 - Curva Granulométrica (Próprio autor, 2019)

3.1 Resistência à compressão dos corpos de prova cilíndricos

Na Figura 3 retrata o comportamento da resistência média dos corpos de prova cilíndricos, em função do traço do concreto aos 14 dias.

A Tabela 2 retrata os valores adquiridos na realização do presente ensaio.

\begin{tabular}{|c|c|c|c|c|}
\hline $\begin{array}{c}\text { Corpo de } \\
\text { prova }\end{array}$ & $\begin{array}{c}\text { Tensão 1 } \\
\text { (MPa) }\end{array}$ & $\begin{array}{c}\text { Tensão 2 } \\
\text { (MPa) }\end{array}$ & $\begin{array}{c}\text { Tensão 3 } \\
\text { (MPa) }\end{array}$ & $\begin{array}{c}\text { Média } \\
\text { (MPa) }\end{array}$ \\
\hline Convencional & 31,03 & 29,70 & 28,57 & $\mathbf{2 9 , 7 7}$ \\
\hline $\begin{array}{c}5 \% \text { de pó de } \\
\text { concha de } \\
\text { mariscos }\end{array}$ & 31,97 & 26,74 & 14,85 & $\mathbf{2 4 , 5 2}$ \\
\hline $\begin{array}{c}10 \% \text { de pó de } \\
\text { concha de } \\
\text { mariscos }\end{array}$ & 30,28 & 31,49 & 32,00 & $\mathbf{3 1 , 2 5}$ \\
\hline $\begin{array}{c}15 \% \text { de pó de } \\
\text { concha de } \\
\text { mariscos }\end{array}$ & 29,90 & 33,32 & 25,25 & $\mathbf{2 9 , 4 9}$ \\
\hline
\end{tabular}




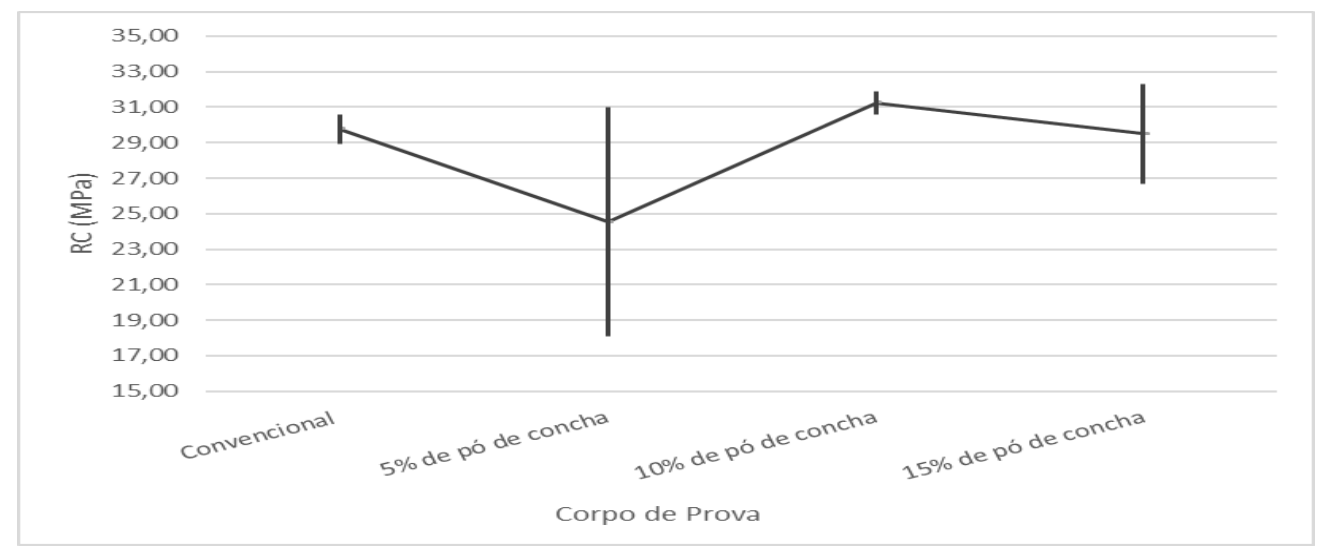

Figura 3 - Resistência à compressão com desvio padrão (Próprio autor, 2019)

Observando-se a análise dos resultados ensaiados aos 14 dias expostos na Figura 3, a resistência à compressão do concreto referente a $10 \%$ com adição de pó das conchas de mariscos apresentou um aumento de aproximadamente $5 \%$ em relação ao concreto convencional. Pode-se analisar também a amostra de $5 \%$ mostrou uma redução de resistência de $18 \%$ em relação ao concreto convencional, assim como a amostra de $15 \%$ que também apontou redução de $1 \mathrm{MPa}$. Para uma melhor análise dos resultados é necessário ensaios como composição do pó de marisco bem como a trabalhabilidade do concreto. Em estudos futuros deve-se utilizar uma maior gama de corpos-de-prova para se investigar a perda acentuada de resistência na amostra de $5 \%$.

O pó das conchas de mariscos é formado por carbonato de cálcio (CaCO3), que devido ao tamanho e formato das partículas, conferem maior compacidade, melhor trabalhabilidade e menor tendência a fissuração em argamassas e concretos (LIAH, 2016).

Nas Figuras 4, 5 e 6 têm-se as amostras dos rompimentos dos corpos de prova de concreto convencional PT1 (Pó das conchas Traço 1) e com adição de 5\% PT2 (Pó das conchas Traço 2), 10\% PT3 (Pó das conchas Traço 3) e 15\% PT4 (Pó das conchas Traço 4) de pó das conchas de mariscos em substituição a areia

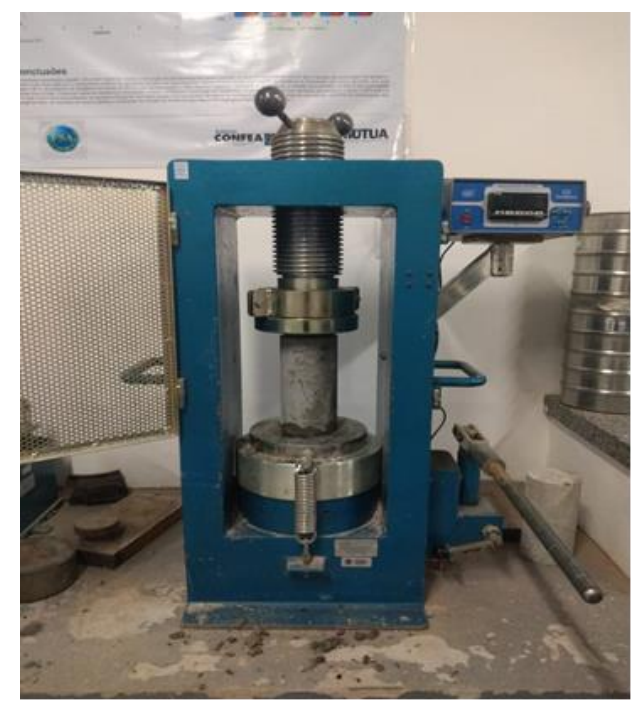

Figura 4 - Equipamento para a determinação a resistência a compressão (Próprio autor, 2019) 


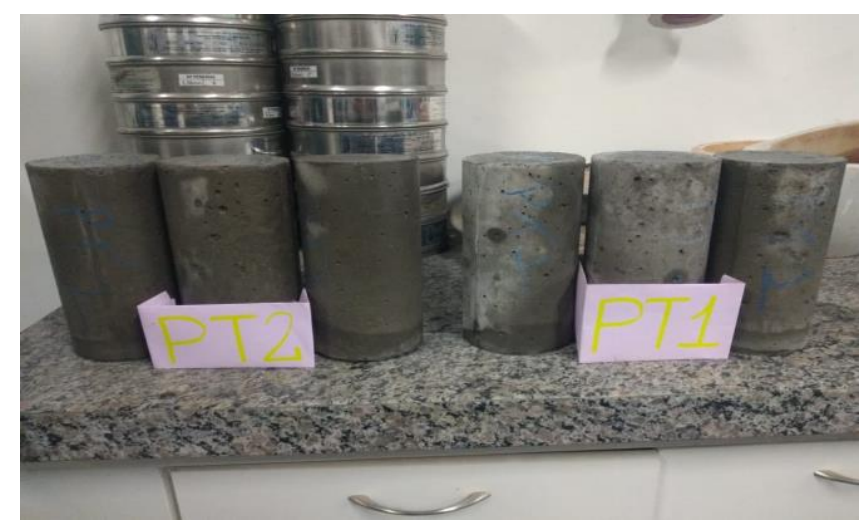

Figura 5 - Corpos de prova convencionais e com 5\% de pó das conchas (Próprio autor, 2019)

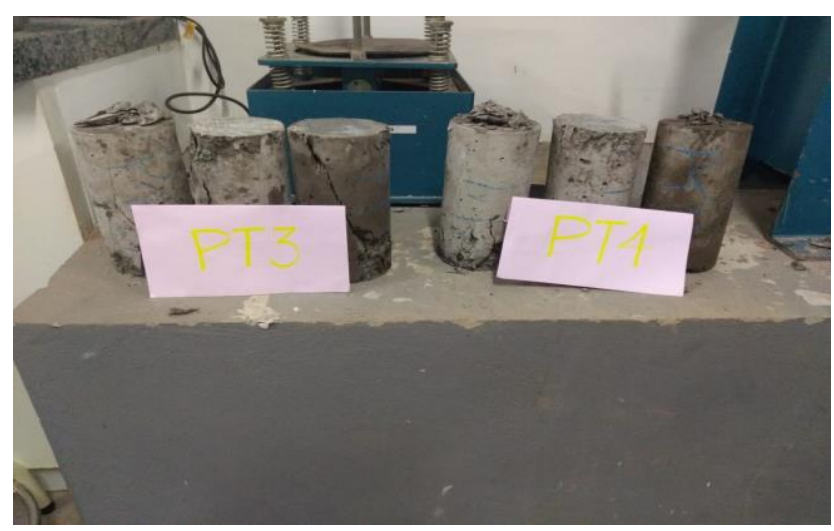

Figura 6 - Corpos de prova de 10\% e 15\% de pó das conchas rompidos (Próprio autor, 2019)

\section{Considerações Finais}

Este artigo certificou que é um caminho viável a utilização de pó de concha de marisco em substituição parcial da areia na composição do concreto. Dessa forma, dando destinação econômica para as conchas de mariscos que são descartados de forma irregular agredindo o meio ambiente.

A casca de marisco é rica em carbonato (CACO3), logo esse carbonato pode ser empregado em diversas atividades, como por exemplo, na indústria da construção civil no processo de fabricação de argamassas, blocos, tintas, vidros e até mesmo em concreto, mas tendo em vista seu descarte de maneira adequada. Portanto também se pode utilizar parcialmente ou totalmente do agregado miúdo, triturando as conchas.

Os resultados obtidos nos ensaios de compressão foram aceitáveis dentro da funcionalidade do concreto não estrutural. Os concretos com adição de conchas de mariscos podem ser utilizados em blocos de vedação sem função estrutural, onde a resistência exigida é 2.0Mpa e podendo ser utilizado em camadas de regularização, nivelamento de bases e contrapisos.

Foi constatado que houve reduções das resistências nos traços de $5 \%$ e $15 \%$ de substituição do pó de concha de marisco em relação ao traço tradicional. Portanto, conclui-se que este estudo serve de base para futuras pesquisas e investimentos do setor público e/ou privado com objetivos de atender os requisitos da lei 12.305/2010 na realização dos planos de gerenciamento de resíduos sólidos. Pode-se analisar a viabilidade econômica, levando em conta transporte e trituração do material, assim como também um estudo relacionado com a forma de tratamento do material antes de ser utilizado, análises mais detalhadas, a fim de se obter mais possibilidades, avaliando o desempenho na sua aplicação ao longo do tempo. 


\section{Referências}

ANGULO, Sérgio Cirelli; ZORDAN, Sérgio Eduardo; JOHN, Vanderley Moacyr. Desenvolvimento sustentável e a reciclagem de resíduos na construção civil. Anais...São Paulo: IBRACON, 2001.

BATISTA, B. B. et al. "Bloco Verde": reaproveitamento de resíduos da construção civil e de conchas de ostras e mariscos, 2008.2 Disponível em: <https://siambiental.ucs.br/congresso/getArtigo.php?id=43\&ano=_primeiro>. Acesso em: 19 fev. 2019.

CODEVASF. Marisqueiras trabalham em unidade produtiva instalada pela Codevasf no Piauí, 2013. Disponível em: <http://www.codevasf.gov.br/noticias/2013/marisqueiras-trabalham-em-unidade-produtiva-instaladapela-codevasf-no-piaui/>. Acesso em: 19 fev. 2019.

LIAH, E. R. Notas de Aula - Cimento Portland. 2016. Potifícia Universidade Católica de Goiás. Goiânia-GO. MOTA, J. C. et al. Características e impactos ambientais causados pelos resíduos sólidos: uma visão conceitual, 2009. Disponível em: <https://aguassubterraneas.abas.org/asubterraneas/article/view/21942>. Acesso em 19

PORTAL DO CONCRETO. Concreto de Alta Resistência Inicial. s/d. Disponível em: . Acesso em: 21 abr. 2016. fev. 2019.

ROCHA, J. C.;CHERIAF, M. Utilização de Resíduos na Construção Habitacional. Porto Alegre: Coletânea Habitare, 2003.

SANT'ANNA, F. S. P. et. al. Projeto Valorização dos Resíduos da Maricultura. SubProjeto 3: Soluções Tecnológicas Para o Aproveitamento de Conchas de Ostras. Laboratório de Gestão Ambiental na Indústria. Departamento de Engenharia Sanitária e Ambiental - Universidade Federal de Santa Catarina. Florianópolis - SC, Dezembro, 2007.

SANTOS, A. P. et al. Alternativas de aproveitamento das conchas de marisco de Anomalocardia flexuosa (Linnaeus, 1767) como material agregado para a elaboração de tijolos ecológicos na comunidade de marisqueiras do Renascer, Cabedelo - PB.Gaia Scientia, 2017,v11, n. 1, p. 77-86.

SANTOS, L. A. Problemática e perspectivas dos resíduos sólidos das conchas de mariscos originados da mariscagem nas comunidades tradicionais em salinas da Margarida-BA. 2013. Dissertação (Mestrado em Geografia)- Universidade Federal da Bahia, Salvador-BA.

TESSARI, J. Utilização de poliestireno expandido e potencial de aproveitamento de seus resíduos na construção civil, 2006. Dissertação (mestrado) - Universidade Federal de Santa Catarina, Florianópolis-SC.

VECHI, N. R., GALLARDO, A. L., \& TEIXEIRA, C. E. Aspectos ambientais do setor da construção civil: Roteiro para a adoção de sistema de gestão ambiental pelas pequenas e médias empresas de prestação de serviços. Sistemas \& Gestão, 2016. p.17-30 